\title{
Analysis and design of directive antenna using frequency selective surface superstrate
}

\author{
Siti Rohani Tajuddin, S. N. Azemi, P. J. Soh, C.B.M.Rashidi, A Abdullah Al-Hadi \\ Advanced Communication Engineering Center (ACE), School of Computer and Communication Engineering, \\ University Malaysia Perlis, Malaysia
}

\begin{tabular}{ll} 
Article Info & ABSTRACT \\
\cline { 3 - 3 } Article history: & $\begin{array}{l}\text { The design of directive antenna using Frequency Selective Surface (FSS) } \\
\text { superstrate is proposed in this project. The suitable design FSS as superstrate }\end{array}$ \\
Received Sep 26, 2018 & $\begin{array}{l}\text { layer is very important to enhance the high directivity and narrow bandwidth } \\
\text { on the antenna. By using the FSS layer to design the superstrate layer, } \\
\text { there are able to determine the reflection coefficient accordingly to the } \\
\text { Accepted Jan 23, } 2019\end{array}$ \\
\begin{tabular}{l} 
desired frequency \\
\hline
\end{tabular}
\end{tabular}

Keywords:

Directive antenna

Frequency selective surface

Incident angle

\section{Corresponding Author:}

Saidatul Norlyana Azemi,

Advanced Communication Engineering Center (ACE),

School of Computer and Communication Engineering,

University Malaysia Perlis, Malaysia.

Email: snorlyana@unimap.edu.my

\section{INTRODUCTION}

FSS is known as metamaterial superstrate. It is not an antenna; it is a filter that used in microwave and optics applications. The filtering response of FSS can be categorized into a low pass, a high pass, a bandpass, and a band stop filter [1] that depend on their physical structure, geometry, and material.

The application of FSS is used in satellite communication systems that need an antenna with the directivity comparable to parabolas using KU - band: $12-18 \mathrm{GHz}$. Since parabolas are quite bulky and more complex structures for the design of three-dimensional directive antennas for microwave telecommunications applications. Therefore, FSS can be pairing by an antenna to pass the necessary signal and reject an unwanted signal. FSS superstrate had been applying to the wireless system such as Wireless Local Area Network (WLAN) that operating between $2.45 \mathrm{GHz}(2.4-2.484 \mathrm{GHz})$ and $5.2 \mathrm{GHz}(5.15-5.35 \mathrm{GHz})$ and World Interoperability for Microwave Access (Wi-Max) was operated at $2.5 \mathrm{GHz}$ and $5.8 \mathrm{GHz}[2]$.

The directive antenna is an antenna that radiates or receives electromagnetic waves that equal to its directivity when transmitting. In electromagnetics, the parameter of directivity antenna is to measures the rate of radiation that emitted to the concentration to a single direction. In another word, an antenna's directivity is a component of its gain and also efficiency. It is an important to measure because many antennas are designed to radiate electromagnetic waves in a single direction or over a narrow-angle [3]. FSS structure is a good alternative to dielectric layers and high directive resonator antennas to ensure it in a compact size and easy to fabricate. In every single and multilayer, FSS has been proposed as superstrate layer over an antenna to enhance its directivity at the desired frequency [6]-[8].

The enhancement of antennas with dielectrics, resonators and periodic elements become attention of many researchers. These are because the antennas are easy to fabricate, low cost and light in weight. 
The properties of antennas nowadays are to improve directivity, radiation pattern, and superstrate surface. In some application, the directive antenna is required for long-range transmission. Nevertheless, often directive antenna is bulky and need to fabricate mechanically. In the last few decades, the difficulties and a huge problem that had been faced with this design of the antenna are a mechanical fabrication and it not suitable for wireless system application due to the complex size of the helical antenna compared to operating wavelength. In addition, the dual frequency that had been produced was not necessary to design directive antenna [9].

Moreover, dielectric EBG antenna was commonly used as a superstrate layer. However, it is difficult to fabricate and commercialization because of the complex low-dielectric constant was required to support an EBG structure on the antenna. Compared with an array antenna, the researcher also utilized that 1Dimension dual EBG resonator was designed for realizing the higher operating frequency and to provide large bandwidth radiated [10].

Therefore, the FSS was early introduced as a replacement of dielectric EBG to improve directivity of gain. There is much easier to fabricate and it has same transmission and reflection characteristics. In addition, the advantage of an FSS superstrate is a more compact and less thickness antenna composite compared to dielectric EBG counterpart.

\section{DIRECTIVE ANTENNA USING FREQUENCY SELECTIVE SURFACES}

The dimension of centered connector FSS allows an additional design parameter enables enhanced control of TE and TM responses without the need for external dielectric matching layer. These properties give the absorb/transmit FSS a clear advantage over conventional FSS. In order to obtain a good fundamental centered connector design the initial comprehensive parametric studies were carried out experimentally using CST Microwave Studio Suite simulation software. The calculation is done to determine the size of the element shape to use in designing an FSS. It is depending on the frequency and the thickness of the substrate. The calculation of parameter is shows following as [11]:

a. Calculation of width, W:

$$
\begin{aligned}
& W=\frac{1}{2 f(\sqrt{\varepsilon \sigma \mu o})} \sqrt{\frac{2}{\varepsilon r+1}} \\
& W=\frac{c}{2 f o \sqrt{\frac{(\varepsilon r+1)}{2}}} \\
& W=34.77 \mathrm{~mm}
\end{aligned}
$$

b) Calculation of effective dielectric constant

$$
\begin{aligned}
& \xi e f f=\left(\frac{\varepsilon r+1}{2}\right)+\left[\left(\frac{\xi r+1}{2}\right)\left(1+12 \frac{h}{W}\right)^{-0.5}\right] \\
& \xi e f f=4.78
\end{aligned}
$$

c) Calculation of line extension

$$
\Delta L=0.42 h\left(\frac{(\xi e f f+0.3)\left(\frac{W}{h}+0.264\right)}{(\xi e f f-0.258)\left(\frac{W}{h}+0.8\right)}\right)
$$

$$
\Delta L=0.76 \mathrm{~mm}
$$

d) Calculation of Length, L

$$
\begin{aligned}
L & =\frac{1}{2 f(\sqrt{\xi e f f} \sqrt{\xi o} \sqrt{\mu o})}-2 \Delta L \\
L & =25.25 \mathrm{~mm}
\end{aligned}
$$


Where:

$$
\begin{array}{ll}
c= & \text { velocity of light in free space } \\
\varepsilon o= & \text { relative permittivity of constant } \\
\varepsilon r= & \text { relative permittivity of substrate } \\
\mu o= & \text { relative permeability of constant } \\
h= & \text { thickness of substrate } \\
f o= & \text { frequency at free space } \\
\tan \delta= & \text { loss tangent }
\end{array}
$$

e) Calculation of Size FSS

$$
\begin{aligned}
& \lambda=\frac{c}{f}=\frac{3 \times 10^{8} \mathrm{~ms}^{-1}}{2.7 \mathrm{GHz}}=111 \mathrm{~mm} \\
& \text { Size FSS }=\frac{\text { Length }}{\lambda}=\frac{25.25 \mathrm{~mm}}{111 \mathrm{~mm}}=227.48 \mathrm{~mm}
\end{aligned}
$$

Where: $\lambda=$ wavelength $\mathrm{C}=\left(3 \times 10^{8}\right)$ Speed of light $\mathrm{f}=$ frequency, $\mathrm{Hz}$

\section{DEVELOPMENT OF FREQUENCY SELECTICE SURFACE}

\subsection{Design Of Directive Antenna Without FSS}

Designing directive antenna by microstrip antenna technique. Microstrip antenna has the advantage of light weight, easier, and familiar with all kinds of carrier aircraft and satellite [15]. The material of the patch is copper which is ductile, have high temperature ability and good electrical conductivity. Besides, operation frequency is $2.68 \mathrm{GHz}$, while dielectric constant substrate (FR-4) which $\varepsilon r=4.3$. The Figure 1 is shown the design directive antenna microstrip, while the Table 1 is shown listed of parameter for directive antenna design.

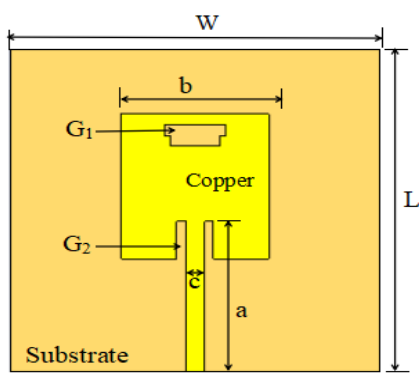

Figure 1. The design of directive antenna by microstip antenna
Table 1. The List of Parameters of Directive

\begin{tabular}{ccc}
\multicolumn{3}{c}{ Antenna Design } \\
\hline Parameter & Symbol & Size \\
\hline Thickness of substrate & $\mathrm{Ht}$ & $1.6 \mathrm{~mm}$ \\
Length of substrate & $\mathrm{L}$ & $60 \mathrm{~mm}$ \\
Width of substrate & $\mathrm{W}$ & $60 \mathrm{~mm}$ \\
Height of conducting element & $\mathrm{H}$ & $0.035 \mathrm{~mm}$ \\
Feedline & $\mathrm{a}$ & $28 \mathrm{~mm}$ \\
Patch antenna dimention & $\mathrm{b}$ & $24 \mathrm{~mm}$ \\
Width of the feedline & $\mathrm{c}$ & $3 \mathrm{~mm}$ \\
Length of Gap 2 & $\mathrm{G}_{2}$ & $1.5 \mathrm{~mm}$ \\
Area of Gap 1 & $\mathrm{G}_{1}$ & $40 \mathrm{~mm}$ \\
\hline
\end{tabular}

\subsection{Design Frequency Selective Surface (FSS)}

The centered connector FSS design is propose by reasoning the by bandstop characteristics. The modification to this length changes the frequency response characteristic of FSS, allowing a better S11 response to be accomplished, in order to improve the gain and also directivity of the directive antenna; the structure is modified by tapering the centered connector shape element as the superstrate of FSS. The Figure 2 is shown the design of FSS element shape. By creating a 2D structure, it proposed that FSS will provide better transmission for a narrow range of bandwidth. Thus, Table 2 is shown the transmittance from the centered connector FSS to improve that the return loss is less $-10 \mathrm{~dB}$ at center frequency which is 2.68 GHz.surfaces. 


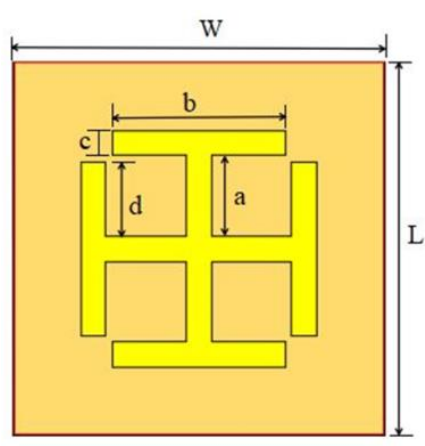

Table 2. The List of Parameters of FSS Design

\begin{tabular}{ccc}
\hline Parameter & Symbol & Size \\
\hline Thickness of substrate & $\mathrm{Ht}$ & $1.6 \mathrm{~mm}$ \\
Length of substrate & $\mathrm{L}$ & $60 \mathrm{~mm}$ \\
Width of substrate & $\mathrm{W}$ & $60 \mathrm{~mm}$ \\
Height of conducting element & $\mathrm{H}$ & $0.035 \mathrm{~mm}$ \\
Length of FSS (a) & $\mathrm{a}$ & $16 \mathrm{~mm}$ \\
Length of FSS (d) & $\mathrm{d}$ & $10 \mathrm{~mm}$ \\
Width of FSS (b) & $\mathrm{b}$ & $28 \mathrm{~mm}$ \\
Width of FSS (c) & $\mathrm{c}$ & $4 \mathrm{~mm}$ \\
\hline
\end{tabular}

Figure 2. The centered connector shape of FSS element

\subsection{Antenna Design With Frequency Selective Surface (FSS)}

The microstrip patch antenna needs the FSS to overcome its weakness which is to improve directivity. A reflector FSS will react as a bandstop filter which is not allow frequency at specific bandwidths designated for the FSS to pass through the plane. The directivity and gain depend on the reflection from the FFS as well as the distance of the patch from the ground plane. The Figure 3 is shown the combined and simulated design of directive antenna using FSS superstrate. These design have been created and simulated by using CST Microwave Suite software.

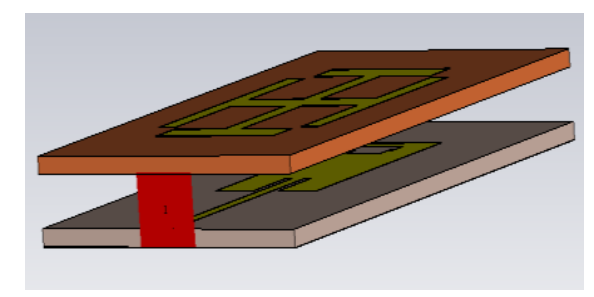

Figure 3. The design of directive antenna and FSS superstrate

\section{RESULT AND DISCUSSION}

The directive antenna had been design and simulate as shown as Figure 1 by using CST Microwave Suite software. From the simulation, the return loss or reflection coefficient, $\mathrm{S} 11$ is equal to $-12.35 \mathrm{~dB}$ at operating frequency $2.67 \mathrm{GHz}$. The realized gain is $0.61 \mathrm{~dB}$, gain (IEEE) is $0.88 \mathrm{~dB}$, and directivity is $6.17 \mathrm{~dB}$. The Figure 4, Figure 5(a), (b)and Figure 6(a), (b) are shown the graph/illustration of S-parameter, 3-Dimension farfield, polar E-field and $\mathrm{H}$-field of simulated directive antenna.

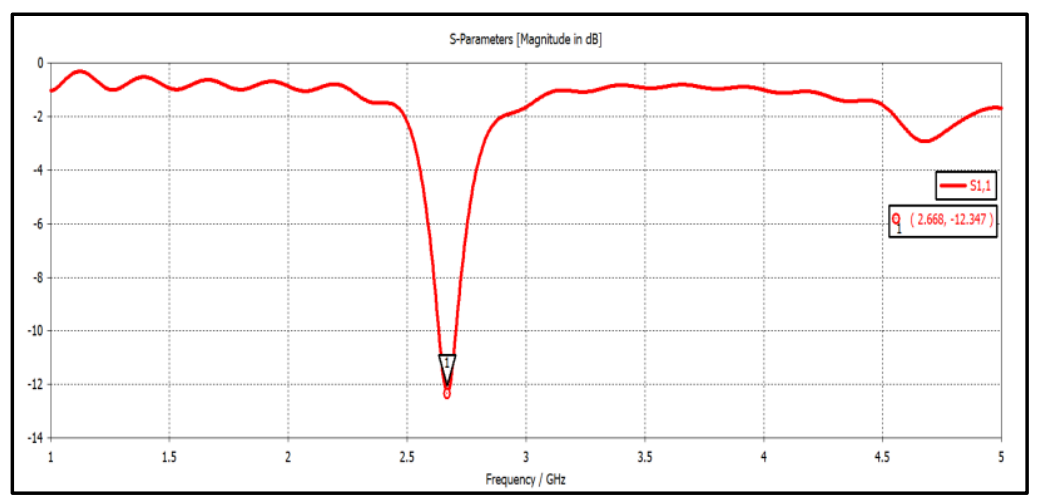

Figure 1. The graph of S-parameter which is return loss, $\mathrm{S} 11$ at $2.67 \mathrm{GHz}$ 


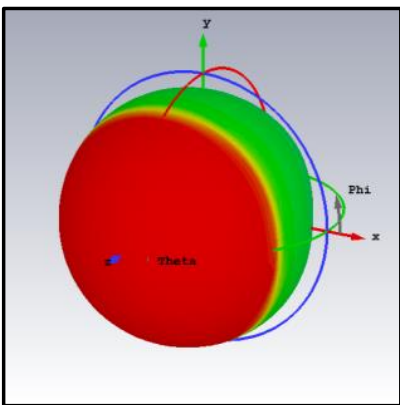

(a)

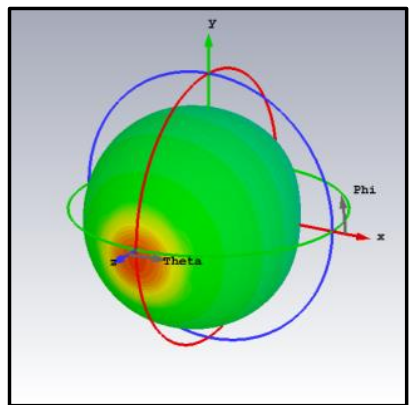

(b)

Figure 2. The illustration of 3-Dimension farfield at $2.67 \mathrm{GHz}$ with (a)directivity $=6.17 \mathrm{~dB}$ and (b) Gain (IEEE) $=0.88 \mathrm{~dB}$

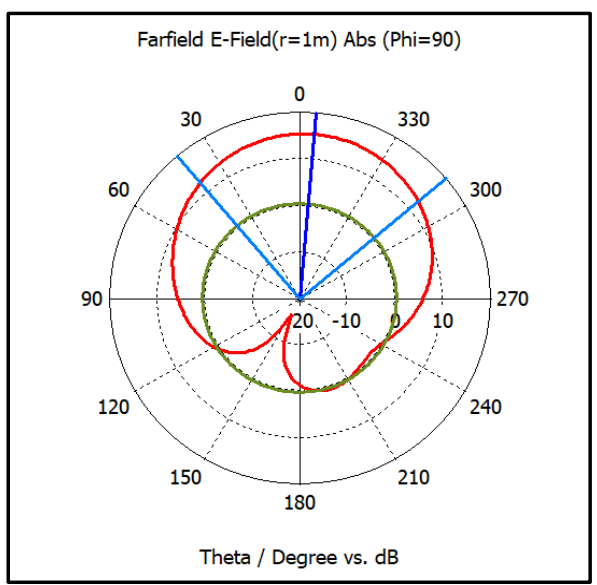

(a)

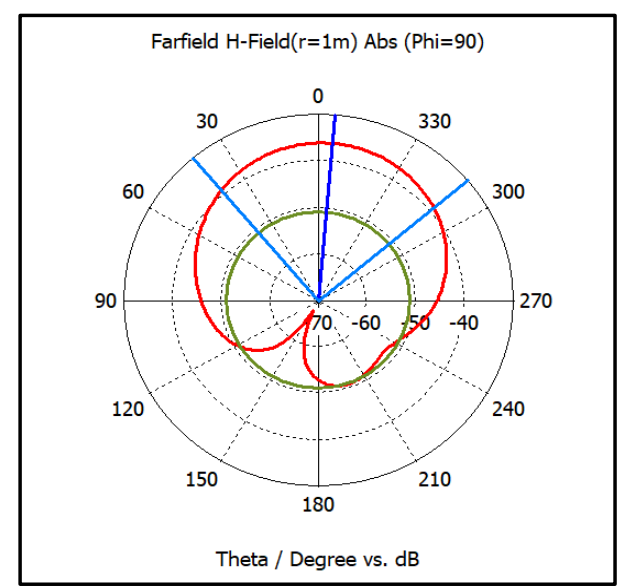

(b)

Figure 3. The illustration of polar farfield at 2.67GHz with (a) E-field and (b)H-field

The directive antenna had been design and simulate as shown as Figure 1 by using CST Microwave Suite software. From the simulation, the return loss or reflection coefficient, S11 is equal to $-15.49 \mathrm{~dB}$ at operating frequency $2.68 \mathrm{GHz}$. The realized gain is $2.36 \mathrm{~dB}$, gain (IEEE) is $2.84 \mathrm{~dB}$, and directivity is $6.57 \mathrm{~dB}$. The Figure 7, Figure 8(a), (b) and Figure 9(a) and (b) are shown the graph/illustration of S-parameter, 3-Dimension far field and polar E-field and H-field of simulated directive antenna using FSS.

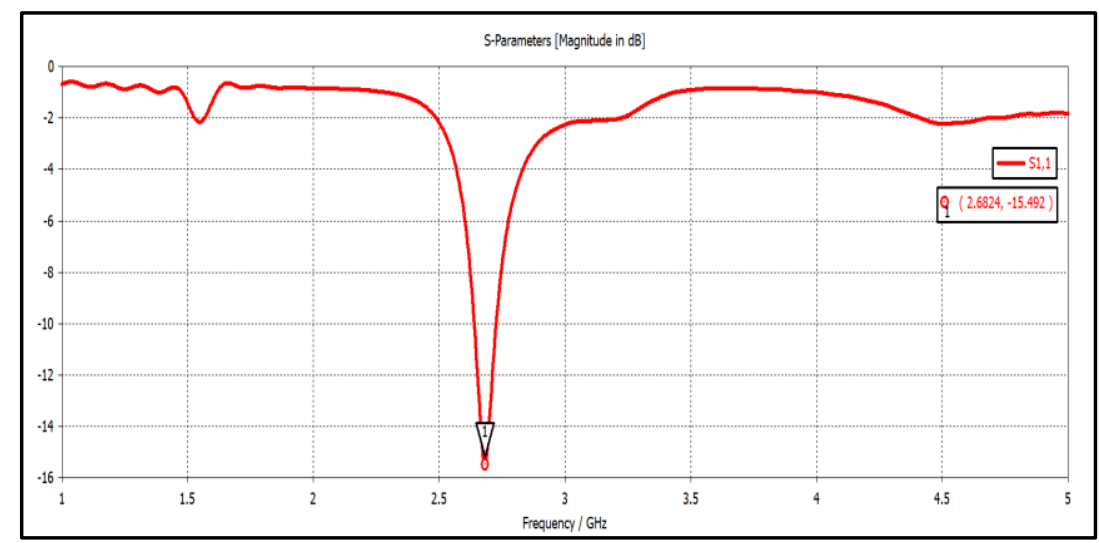

Figure 4. The graph of S-parameter which is return loss, $\mathrm{S} 11$ at $2.68 \mathrm{GHz}$ 


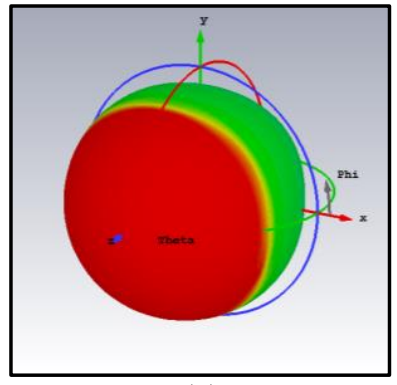

(a)

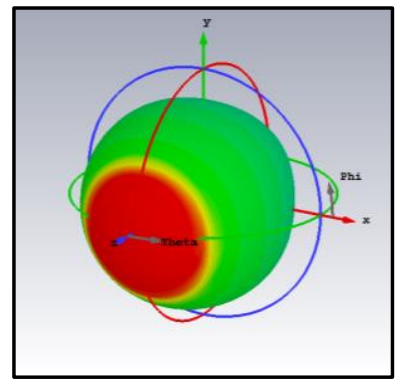

(b)

Figure 5. The Illustration of 3-Dimension Farfield at foperating=2.68 GHz with (a)Directivity=6.57dB and (b) Gain $(\mathrm{IEEE})=2.48 \mathrm{~dB}$

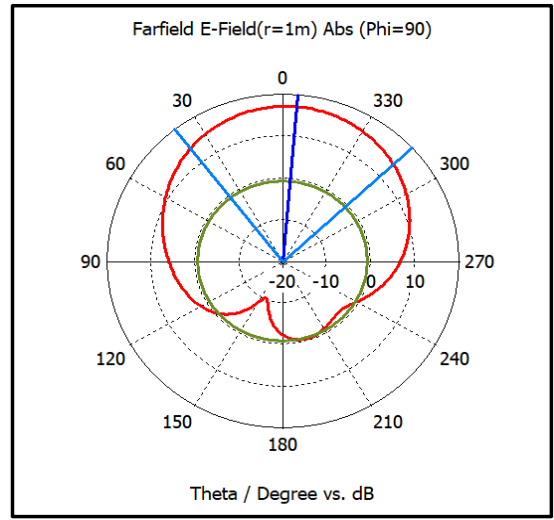

(a)

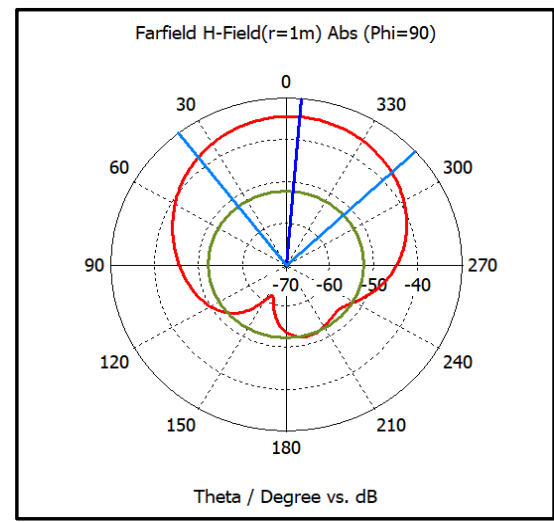

(b)

Figure 6. The illustration of polar farfield at foperating=2.67 GHz with (a) E-field and (b)H-field

The performance of proposed directive antenna combined with FSS superstrate element has been compared with reference directive antenna which is microstrip in terms of return loss, gain and directivity. It has been observed that proposed directive antenna using FSS superstrate have better results as compared to reference antenna and configuration. The performance of proposed directive antenna using FSS superstrate designs and reference antenna has been compared in the Table 3.

Table 3. Comparison result between Directive Antenna \& FSS

\begin{tabular}{ccc}
\hline Parameter & Directive antenna without FSS & Directive antenna with FSS \\
\hline Return loss, $\mathrm{S}_{11}$ & $-12.35 \mathrm{~dB}$ & $-15.49 \mathrm{~dB}$ \\
Directivity & $6.17 \mathrm{~dB}$ & $6.57 \mathrm{~dB}$ \\
Gain, IEEE & $0.88 \mathrm{~dB}$ & $2.48 \mathrm{~dB}$ \\
Realized Gain & $0.61 \mathrm{~dB}$ & $2.36 \mathrm{~dB}$ \\
\hline
\end{tabular}

In this cases, the FSS plane cover all the wave radiated with proposed of low losses during the transmission. The main role of the FSS is either to be a filter or a reflector. If the antenna act as a filter, it will assist to optimize the wave while a reflector FSS will not allow frequency at specific bandwidths designated for the FSS to pass through the planer. While, the microstrip directive antenna needs the FSS to overcome its weakness to improve the return loss, higher gain and directivity. It likewise helps to maintain and optimize the beam of the microstrip directive antenna.

\subsection{Fabrication Design and Measurement Result}

The fabrication and measurement had been done for directive antenna with Frequency Selective Surface. Shown in Figure 9 is the fabricated antenna. Table 4 shows the comparison between simulation and measurement result of the directive antenna with the FSS. The purpose of measurement is to ensure that the 
result of the simulation can be proof. Based on the simulated result, the operating frequency is $2.68 \mathrm{GHz}$, return loss is $-15.51 \mathrm{dBi}$, VSWR is 1.402 and reflection coefficient is 0.168 . While the measured result that had been obtained is are operating frequency is $2.76 \mathrm{GHz}$, the return loss equal to $-15.27 \mathrm{dBi}$, VSWR is 1.417 and reflection coefficient is 0.172 . Next, Figure 10 shows the result of S11-parameter that had been displayed on the Network Analyzer.

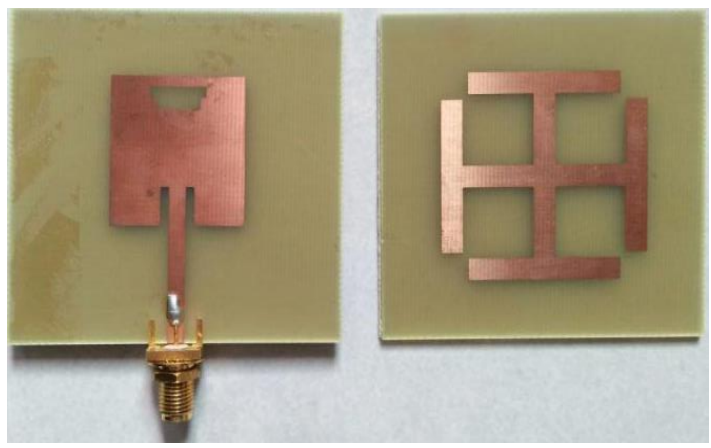

Figure 9. The Fabricated design of directive antenna and fss superstrate layer on FR-4 substrate

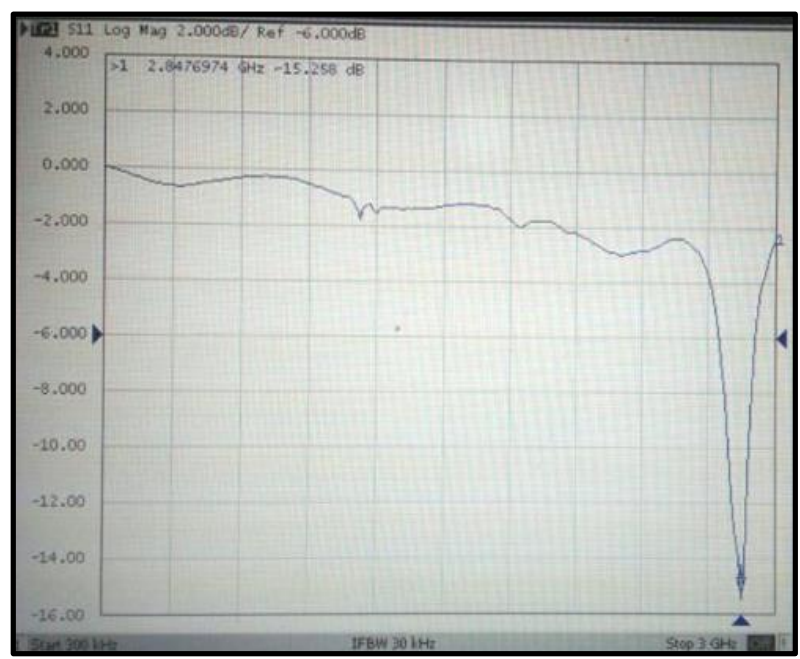

Figure 10. Measurement result of S11 using network analyzer

Table 4. The Comparison between Simulation Result and Measurement Result

\begin{tabular}{ccc}
\hline Parameter & Directive antenna without FSS & Directive antenna with FSS \\
\hline Frequnecy & $2.68 \mathrm{GHz}$ & $2.84 \mathrm{GHz}$ \\
Return loss, $\mathrm{S}_{11}$ & $-15.51 \mathrm{dBi}$ & $-15.27 \mathrm{dBi}$ \\
Reflection Coefficient & 0.168 & 0.172 \\
VSWR & $1.403: 1$ & $1.417: 1$ \\
\hline
\end{tabular}

\section{CONCLUSION}

The scope of the project was to observe new method with parametric studies to get the best performing of directive antenna using FSS. There are a few essential parameters in designing FSS to meet specification such as unit cell of FSS. The Figure 3 is shown illustration how the directive antenna combined with FSS superstrate. The results show that compared with reference antenna, the directivity of the antenna loading FSS as its superstrate layer is enhanced from $6.17 \mathrm{~dB}$ to $6.57 \mathrm{~dB}$ and gain has improved from $0.88 \mathrm{~dB}$ to $2.48 \mathrm{~dB}$. However, the bandwidth is not affected.

\section{ACKNOWLEDGEMENTS}

The authors gratefully acknowledge use of the services and facilities of the Advanced Communication Engineering Centre (ACE) CoE, School of Computer and Communication Engineering, Universiti Malaysia Perlis (UniMAP). This project also been funded by Fundamental Research Grant Scheme (FRGS) 9003-00545.

\section{REFERENCES}

[1] C. Huang, Z. Zhao and X. Luo, "The application of Adaptive Frequency Selective Surface Superstrate In The Directive Patch Antenna,"2009 3rd IEEE International Symposium on Microwave, Antenna, Propagation and EMC Technologies for Wireless Communications, Beijing, 2009, pp. 631-634, [Access 24 Aug. 2017].

[2] B. Peswani, S. Yadav and M. M. Sharma, "A Novel Band Pass Double-Layered Frequency Selective Superstrate for WLAN applications," 2014 5th International Conference - Confluence The Next Generation Information Technology Summit (Confluence), Noida, 2014, pp. 447-451, [Access 24 Aug. 2017]. 
[3] H. Boutayeb, T. A. Denidni, K. Mahdjoubi, A. C. Tarot, A. R. Sebak and L. Talbi, "Analysis and design of a cylindrical EBG-based directive antenna," in IEEE Transactions on Antennas and Propagation, vol. 54, no. 1, pp. 211-219, Jan. 2006, [Access 25 Aug. 2017].

[4] A. Pirhadi, F. Keshmiri and M. Hakkak, "Design of Dual-band Low Profile High Directive EBG Resonator Antenna, using Single Layer Frequency Selective Surface (FSS) superstrate," 2006 IEEE Antennas and Propagation Society International Symposium, Albuquerque, NM, 2006, pp. 3005-3008, [Access 30 Oct. 2017].

[5] Lee, Y. J., J. Yeo, R. Mittra, and W. S. Park, "Design of High Directivity Electromagnetic Band Gap (EBG) Resonator Antenna using a Frequency Selective Surface (FSS) superstrate," Microwave and Optical Technology Letters, Vol. 43, No. 6, 462-467, 2004, [Access 30 Oct. 2017].

[6] Y. J. Lee, J. Yeo, R. Mittra, and W. S. Park, "Design of a Frequency Selective Surface (FSS) Type Superstrate for Dual-band Directivity Enhancement of Microstrip Patch Antennas," IEEE AP-S International Symposium and USNC/URSI National Radio Science Meeting, Washington DC, July, 2005,[Access 1st Nov. 2017].

[7] Y. J. Lee, D. H. Lee, J. Yeo, W. S. Park, and R. Mittra, "Design of a Frequency Selective Surface (FSS) Superstrate with Ring-shaped elements for Directivity Enhancement and Low Side-Lobe Level of a Circular Polarization Antenna," International Symposium on Microwave and Optical Technology, Fukuoka, Japan, Vol A-02, pp.11-14, August 22-25, 2005.

[8] Y. J. Lee, J. Yeo, R. Mittra and W. S. Park, "Thin Frequency Selective Surface (FSS) Superstrate with Different Periodicities for Dual-band Directivity Enhancement," IEEE International Workshop on Antenna Technology: Small Antennas and Novel Metamaterial (IWAT), pp. 375-378, March 2005.

[9] M. Bouslama, M. Traii, A. Gharsallah, and T. A. Denidni, "A New FSS Superstrate Structure For Antenna Performance Enhancement," 2015 Radio and Antenna Days of the Indian Ocean (RADIO), Belle Mare, pp. 1-2, 2015.

[10] M. Mokhtar, Ass. Prof., Egyptian Armed Forces, “Analysis Of Cylindrical Frequency Selective Surfaces”, 1998 Fifteenth National Radio Science Conference, Heiwan, Cairo Egypt, pp. 24-26 Feb. 1998.

[11] Munk, B.A., "Frequency selective surfaces; theory and design'; 2005: Wiley- Interscience.

[12] Young Ju Lee, Junho Yeo, R. Mittra, and Wee Sang Park, "Thin Frequency Selective Surface (FSS) Superstrate with Different Periodicities For Dual-Band Directivity Enhancement,"IWAT 2005. IEEE International Workshop on Antenna Technology: Small Antennas and Novel Metamaterials, pp. 375-378, 2005.

[13] N. Guérin, C. Hafner, X. Cui, and R. Vahldieck, "Compact Directive Antennas Using Frequency-Selective Surfaces (FSS)", 201 IEEE. APMC Proceedings, 2005.

[14] Ranjeet Singh, Dr. Simranjeet Singh Tiwana "Design and Performance of a Compact Microstrip Patch Antenna using Circular slots And Stub for RFID Applications”, Page 1-6, Volume 4 Issue 8, SSRG International Journal of Electronics and Communication Engineering (SSRG-IJECE), August 2017.

[15] Xiang-yu Li,Jian Li et. all "High Gain Microstrip Antenna Design by Using FSS Superstrate Layer", 4th International Conference on Computer Science and Network Technology (ICCSNT 2015), 2015. 